\title{
Urban source term estimation for mercury using a boundary-layer budget method
}

\author{
Basil Denzler $^{1}$, Christian Bogdal ${ }^{1}$, Cyrill Kern ${ }^{1}$, Anna Tobler ${ }^{1, a}$, Jing Huo ${ }^{1}$, and Konrad Hungerbühler ${ }^{1}$ \\ ${ }^{1}$ Institute for Chemical and Bioengineering, ETH Zurich, Vladimir-Prelog-Weg 1, 8093 Zurich, Switzerland \\ apresent address: Paul Scherrer Institute, 5232 Villigen PSI, Switzerland
}

Correspondence: Christian Bogdal (christian.bogdal@chem.ethz.ch)

Received: 20 April 2018 - Discussion started: 18 May 2018

Revised: 22 December 2018 - Accepted: 14 February 2019 - Published: 25 March 2019

\begin{abstract}
Mercury is a heavy metal of particular concern due to its adverse effects on human health and the environment. Recognizing this problem, the UN Minamata Convention on Mercury was recently adopted, where signatory countries agreed to reduce anthropogenic mercury emissions. To evaluate the effectiveness of the convention, quantitative knowledge on mercury emissions is crucial. So far, bottom-up approaches have successfully been applied to quantify mercury emission - especially for point sources. Distributed sources make up a large share of the emission; however, they are still poorly characterized. Here, we present a top-down approach to estimate mercury emissions based on atmospheric measurements in the city of Zurich, Switzerland. While monitoring the atmospheric mercury concentrations during inversion periods in Zurich, we were able to relate the concentration increase to the mercury emission strength of the city using a box model. By means of this boundary-layer budget approach, we succeeded in narrowing down the emissions of Zurich to range between $41 \pm 8 \mathrm{~kg} \mathrm{a}^{-1}$ (upper bound) and $24 \pm 8 \mathrm{~kg} \mathrm{a}^{-1}$ (lower bound). Thereby, we could quantify emissions from mixed, diffuse and point-like sources and derive an annual mercury per capita emission of 0.06 to $0.10 \mathrm{~g} \mathrm{a}^{-1}$. The approach presented here has the potential to support authorities in setting up inventories and to validate emission estimations derived from the commonly applied bottom-up approaches. Furthermore, our method is applicable to other compounds and to a wide range of cities or other areas, where sources or sinks for mercury and other atmospheric pollutants are presumed.
\end{abstract}

\section{Introduction}

The UN Minamata Convention on Mercury entered into force in August 2017. It marks a milestone in the ambitions of the global community to protect human health and the environment from the adverse effects of mercury and mercury compounds. The parties to this convention have agreed to control mercury emissions and establish an inventory of emissions from relevant sources. Furthermore, the convention recognizes the need for research and monitoring to increase the state of knowledge regarding the emission and distribution pathways of mercury. Numerous measurement campaigns for atmospheric mercury have been conducted worldwide. They show gaseous elemental mercury (GEM) concentration to be the dominant atmospheric mercury species with a share of more than $90 \%$, while gaseous oxidized mercury (GOM) and particle-bound mercury (PBM) make up a small share of the background air (Gay et al., 2013).

The tools applied in the analysis of these measurement results encompass among others wind rose interpretations, back trajectories and various statistical analyses. Potential sources for mercury can thereby be located but a quantification of their emission strength is not achieved. For testing the effectiveness of an international treaty such as the Minamata Convention, however, quantitative information on emission and changes thereof are crucial. This task of assessing the sources is often left to authorities which follow the guidelines for the bottom-up approach (AMAP/UNEP, 2013). The inventories established with this method are very valuable and so far certainly provide the best and most reliable emission estimates. However, these inventories address emissions usually on a national level and focus heavily on large point sources. Additionally, the apportionment of total 
national emissions to regional emissions is a difficult task, requiring various assumptions. To obtain spatially resolved emissions, two steps are applied. First, mercury emissions are assigned to point sources where possible. Second, socalled "distributed sources", which make up $>80 \%$ of total emissions worldwide, are mapped using a surrogate on the basis of population density data (Wilson et al., 2006; AMAP/UNEP, 2013). Top-down studies confirming the allocation practice of distributed mercury emissions in bottomup inventories are lacking. For scientific requirements, verification and testing of these inventories with other independent methods is necessary, as has similarly been suggested for greenhouse gases (Nisbet and Weiss, 2010). In this work, we present a top-down method that allows quantification of mercury emissions in an urban environment. The goal is to support authorities with the interpretation of their valuable and expensive monitoring studies and to ultimately introduce a top-down method that could help to verify and refine mercury emission inventories regarding distributed emissions. To achieve this refinement, the method has to be applicable to numerous locations worldwide with limited resources. For our model setup we make use of the meteorological phenomenon of a ground inversion. The reduced vertical mixing during high-pressure winter periods or summer nights above ground leads to an accumulation of atmospheric pollutants below the boundary air layer. Inversion effects occur frequently in metropolitan areas all over the world, such as Los Angeles, Beijing, Milan, Mexico City, Tehran or Mumbai, and can lead to adverse effects for the population. In such locations, a boundary-layer budget method (Denmead et al., 1996) can be applied during inversion events to estimate the source strength of these substances, since it is then proportional to their concentration increase. We apply this approach to the city of Zurich, Switzerland, which serves as a representative site for Switzerland, which is in turn representative for an industrialized country in Europe with existing mercury regulation and is also party to the Minamata Convention. Additionally, we can profit from our previous studies, where our model has been extensively validated for the city of Zurich and the top-down approach could successfully be applied to quantify emissions of various anthropogenic pollutants. Our previous studies reported top-down-derived emissions in Zurich for industrial chemicals, including polychlorinated biphenyls (PCBs) (Gasic et al., 2009; Bogdal et al., 2014a; Diefenbacher et al., 2016); flame retardants (Bogdal et al., 2014b; Diefenbacher et al., 2015a); perfluorinated surfactants (Müller et al., 2012; Wang et al., 2012); unintentional combustion byproducts, including polychlorinated dibenzo- $p$-dioxins and dibenzofurans (Bogdal et al., 2014a); or additives of personal care products such as cyclic methylsiloxanes (Buser et al., 2013). Furthermore, this method is not only applicable to Zurich but to a multitude of locations and has successfully been applied to various substances such as PCBs in Chicago (USA), Hazelrigg (UK), Finokalia (Greece), Banja Luka (Bosnia and Herzegovina) (MacLeod et al., 2007; Gasic et al., 2010); cyclic methylsiloxanes in Chicago (USA) (Buser et al., 2014); chloro- and hydrofluorocarbon propellants nearby Zurich (Switzerland) (Buchmann et al., 2003); and methane in London (UK) (Lowry et al., 2001) and St. Petersburg (Russia) (Zinchenko et al., 2002). Wherever smog problems arise such a boundary-layer budget is technically feasible. We hypothesize that mercury has relatively constant emissions and follows the pattern of accumulation during strong inversion periods similarly to the organic pollutants cited before. By developing and applying a box model for the city of Zurich our aim is to derive the emission source strength of Zurich. Furthermore, we extrapolate our findings to all of Switzerland and compare the calculated emissions to reported emissions from bottom-up inventories. Finally, we discuss the applicability of our boundary-layer budget approach in a general context.

\section{Measurements and methods}

\subsection{Measurements}

Gaseous elemental mercury concentrations have been measured from December 2013 until December 2015 at the sampling station of the Swiss National Air Pollution Monitoring Network (NABEL), Zurich Kaserne, Switzerland. It is located in a large courtyard (approximately $9000 \mathrm{~m}^{2}$ ) in the city center of Zurich $\left(47.38^{\circ} \mathrm{N}, 8.53^{\circ} \mathrm{E} ; 409 \mathrm{~m}\right.$ a.s.l.) shielded from highly frequented roads and industrial activities. For decades, the site has provided continuous monitoring of the major air pollutants and a multitude of meteorological parameters, such as the wind speed, used in this study as a model parameter. Previous studies on particulate matter $\left(\mathrm{PM}_{10}\right)$ (Hasenfratz et al., 2015; Mueller et al., 2016), nitrogen oxides $\left(\mathrm{NO}_{x}\right)$ (Mueller et al., 2015) and persistent organic pollutants (Bogdal et al., 2014a; Diefenbacher et al., 2015b, 2016) have shown that the measurement location provides representative background levels for the city of Zurich and is not affected by acute emissions close to the site. For GEM measurements air was sampled through an inlet (2 ma.g.l.) and analyzed using a Tekran ${ }^{\circledR} 2537 \mathrm{X}$ cold vapor mercury analyzer with a detection limit lower than $0.1 \mathrm{ng} \mathrm{m}^{-3}$ stated by the manufacturer. Flow rate was $1.5 \mathrm{~L} \mathrm{~min}^{-1}$ and measurements were taken every $5 \mathrm{~min}$ from alternating cartridges. The instrument was automatically calibrated every $25 \mathrm{~h}$. Additionally, manual calibrations of the permeation source were performed using an external calibration device (Tekran ${ }^{\circledR}$ 2505), and comparison measurements were conducted with an instrument identical in construction to ensure data quality. Furthermore, GEM was measured during a single monitoring campaign (January-February 2016) using the same measurement device on a site in the periphery of Zurich (Zurich zoo; $47.38^{\circ} \mathrm{N}, 8.58^{\circ} \mathrm{E} ; 587 \mathrm{~m}$ a.s.l.), to obtain indications for the background influx of air in Zurich. Methane $\left(\mathrm{CH}_{4}\right)$ and carbon monoxide $(\mathrm{CO})$ measurements 
were provided by NABEL (BAFU/EMPA, 2018). $\mathrm{CH}_{4}$ levels are used as a conservative trace gas to compare to GEM levels, while $\mathrm{CO}$ is used as combustion indicator.

\subsection{Model design}

For the model design, we take advantage of the meteorological conditions of a temperature inversion that can occur during high-pressure periods: a phenomenon where - due to the faster cooling of the earth surface - the temperature profile in the atmosphere becomes inverted. Being higher in density, cold air resides at the surface and temperature increases with height until the boundary-layer top is reached. This leads to a stratification of air masses, where vertical mixing is very low. In Zurich this phenomenon is enhanced by the valley topography, where cold air drains into the depression. The reduced convective mass transfer to the warmer air masses above thus restricts the air volume in direct contact with the surface. In summer this phenomenon usually only occurs during the night. The strong soil heating and the resulting thermal lift break up the inversion soon after daybreak. In winter, with lower sun intensity, inversion conditions can prevail for several days up to weeks, leading to the well known smog problem. With steady emissions at the ground level into the smaller volume of the surface layer, an increase in concentration for air pollutants is observable (Salmond, 2005; MacLeod et al., 2007). This not only accounts for commonly monitored air pollutants such as $\mathrm{CH}_{4}, \mathrm{CO}, \mathrm{NO}_{x}$, volatile organic compounds (VOCs) and aerosols such as $\mathrm{PM}_{10}$, but also for trace chemicals of anthropogenic origin such as persistent organic pollutants (Gasic et al., 2009; Müller et al., 2012; Wang et al., 2012; Bogdal et al., 2014a, b; Diefenbacher et al., 2015a, b), cyclic methylsiloxanes (Buser et al., 2013), or chloro- and hydrofluorocarbons (Buchmann et al., 2003). Under the assumption of constant emissions, the slope of the increase in concentrations is proportional to the emission flux. By setting up a box model, we make use of this circumstance and are able to derive the emission term for the investigated air pollutant. This approach is hereafter also referred to as the boundary-layer budget method.

\subsection{Model parametrization}

Over the course of the measurement period, nine episodes of day-night inversion were identified by visual inspection for the criteria of strong day-night inversion. Only events lasting for a minimum of 4 days were considered. Individual periods show a considerably longer duration of up to 14 days. These events are then reproduced with our previously developed and validated model. While in our previous studies the temporal resolution of the air monitoring was significantly limited (resolution of hours to weeks), we profit here from highly resolved GEM data (5 min resolution). We follow the approach to strip the model to the minimum, and only processes indispensable to the parametrization of the

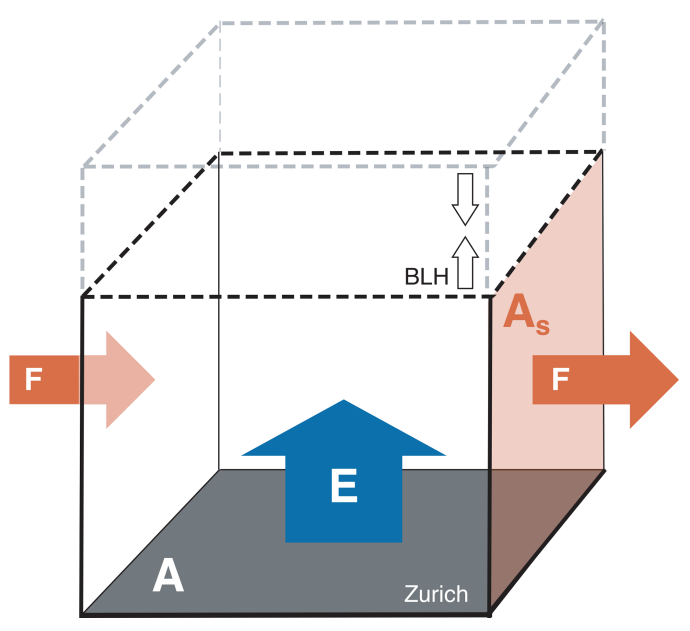

Figure 1. Box model used to estimate GEM emissions $E$ of Zurich. $A$ represents the area of the base and $A_{\mathrm{S}}$ the area of the lateral side of the box. The variable boundary-layer height $(\mathrm{BLH})$ determines the height of the box and $F$ the advective flow.

conditions at hand are incorporated. This lean model approach prevents over-interpretation of model results and the reduced complexity provides a better conceivability of the model. Thereby, we end up with a model consisting of a single box of air that covers an area $A$ of $10 \mathrm{~km} \times 10 \mathrm{~km}$ $\left(100 \mathrm{~km}^{2}\right)$ approximating Zurich's size inhabited by roughly 400000 people (Fig. 1). The box size was chosen to encompass the city's emission sources and has proven to be suitable by previous studies (Wang et al., 2012; Buser et al., 2013; Bogdal et al., 2014b). Based on the national emission inventory (Heldstab et al., 2015), half of the mercury emissions are assumed to stem from mixed sources such as stationary combustion, minor industrial activities and houses distributed all over the city. The other half is assumed to come from a municipal waste incineration plant in the middle of the city, where a chimney (height $90 \mathrm{~m}$ ) leads to a broader distribution. For Zurich this shows an emission profile similar to unintentional combustion byproducts such as polychlorinated dibenzo- $p$-dioxins and dibenzofurans studied in the work of Bogdal et al. (2014b). Since for this study on GEM we only have one measurement location at near surface level, the assumption of a homogeneously mixed air compartment below the nocturnal boundary layer is necessary. The previous studies on dioxins have shown that this assumption is justifiable. Possible stratification, however, remains a source of uncertainty in our model. Emissions of oxidized mercury species such as $\mathrm{HgCl}_{2}$ as well as particulate mercury were not included in the model. Regarding the local emissions of oxidized mercury, we did not have any data available. The only major source would be the municipal waste incineration plant. Considering the flue-gas treatment systems installed, however, we assume stack emissions to be predominantly in the form of GEM (van Velzen et al., 2002). Flue gas is treated with an ESP, SCR, AC, and three-step WFGD, in this order. 
(ESP: electrostatic precipitator, SCR: selective catalytic reduction, AC: activated carbon injection, WFGD: wet flue-gas desulfurization). Regarding the GEM / GOM ratio the effect of flue-gas treatment on mercury emissions is, however, still unclear, leaving some level of uncertainty to our assumption (Zhang et al., 2016). Mercury emissions stemming from reduction of oxidized mercury reservoirs are thus contained in the total GEM emission estimates.

The time-dependent parameters included in the model are (i) the boundary-layer height (BLH), defining the volume of the box; (ii) the wind speed to model advective flux $(F)$ through the box; and (iii) the background concentrations to quantify the concentrations of the advective flux.

The model is operated dynamically with an hourly resolution. Due to the small size of the model area, many parameters usually included in box models can be disregarded. Slow processes such as deposition to soil and water, as well as re-emission from these compartments, are negligible. Atmospheric oxidation of GEM to GOM is excluded as well due to the short residence time of mercury within the considered small model region (less than $1 \mathrm{~h}$ for wind speed of $3 \mathrm{~m} \mathrm{~s}^{-1}$ ). Our own calculations, with a version including atmospheric degradation reactions, show that losses by degradation are negligible in comparison to the advective fluxes.

The focus of the model is on the emission flux, which is directed to the surface air compartment and is kept constant over the course of an inversion period. The goal is to find the emission term that results in a modeled surface GEM concentration best matching the measured concentrations. The emission flux is the only adjustable parameter in the model, whereas all further model parameters are preset and not adapted to improve the fit between model results and field measurements. The root mean square error (RMSE) is used as a measure for optimization in an iterative fitting process. The emission flux resulting in the lowest RMSE is then applied as the city's source term.

\subsubsection{Model setup}

The model includes the following three time-dependent model parameters.

i. The boundary-layer height (BLH) is used as a measure to define the volumes of the air compartment of the model (Fig. 1). In a first model approach, boundarylayer heights are approximated using constant levels for the daylight and nightly period. The height is set to $1500 \mathrm{~m}$ for the convective boundary layer (CBL) during the day from 08:00 (UTC+1) until 20:00 and lowered to $150 \mathrm{~m}$ for the nocturnal boundary layer (NBL) at 21:00. The NBL level is based on common meteorological conditions (Stull, 1988) and our own experiences in previous work (MacLeod et al., 2007; Gasic et al., 2009; Wang et al., 2012; Buser et al., 2013; Bogdal et al., 2014b). A sharp transition is used between NBL and CBL. These heights determine the box vol- ume of the air layer. Changes in the volume of the air compartment are handled such that, in cases of a decline in BLH, the amount of GEM in the volume difference is transferred out of the box. In cases of a rise in the $\mathrm{BLH}$, the GEM concentration in the air compartment is diluted with the corresponding air volume with GEM concentration of background levels.

ii. The advection is determined by the wind speed. Wind speed measurements are conducted above a roof top (33 m a.g.l.). Studies by Benz (1988) and Schuhmacher (1992) in Zurich show that measurements at this height are representative for the mean wind speed for the height profile from 0 to $150 \mathrm{~m}$. As shown later only nightly periods where the BLH is $150 \mathrm{~m}$ are relevant to estimate emissions in Zurich. Wind direction is not taken into consideration. Therefore, advection $F$ is always occurring through a lateral face of the box (Fig. 1) and the flux is obtained by multiplication of its area $A_{\mathrm{s}}$ with the corresponding wind speed $u, F=A_{\mathrm{s}} \cdot u$.

iii. The background concentration is set to a steady level of $1.5 \mathrm{ng} \mathrm{m}^{-3}$. It lies in the lower $10 \%$ quantile of the whole 2-year measurement series in Zurich and no adaption was made for nightly backgrounds. In reality, background concentrations are likely to be higher than this level since also at high wind speeds measurements rarely fall below as we show in Figs. S1 and $\mathrm{S} 2$ in the Supplement. The value of $1.5 \mathrm{ng} \mathrm{m}^{-3}$ lies in the range of what we measured at the outskirts of the city of Zurich (Zurich zoo, median $=1.62 \mathrm{ng} \mathrm{m}^{-3}$, $Q_{0.1}=1.53 \mathrm{ng} \mathrm{m}^{-3}, Q_{0.9}=1.77 \mathrm{ng} \mathrm{m}^{-3}$ ). On the basis of this assumption an upper-bound model run regarding the source strength of the city is calculated. To establish a margin, which restricts the source strength with a realistic lower-bound, background concentrations are raised to the median concentration of $1.8 \mathrm{ng} \mathrm{m}^{-3}$ for a second emission estimate. We are confident that actual emissions reside within the range of these two model runs.

\section{Results and discussion}

\subsection{Measurement series}

GEM levels measured in Zurich from December 2013 until December 2015 show a median concentration of $1.81 \mathrm{ng} \mathrm{m}^{-3}$ $\left(Q_{0.1}=1.55 \mathrm{ng} \mathrm{m}^{-3}, Q_{0.9}=2.36 \mathrm{ng} \mathrm{m}^{-3}\right)$. The concentration gradient for GEM follows a weak diurnal pattern, similar to $\mathrm{CH}_{4}$ concentrations, however, with a more prominent amplitude. Figure 2 shows the diurnal pattern of GEM, $\mathrm{CH}_{4}$ (i.e. conservative tracer) and $\mathrm{CO}$ (i.e. combustion indicator) measurements normalized by their respective mean concentration. The rise in concentrations during nighttime and the minimal concentrations during the afternoon are 

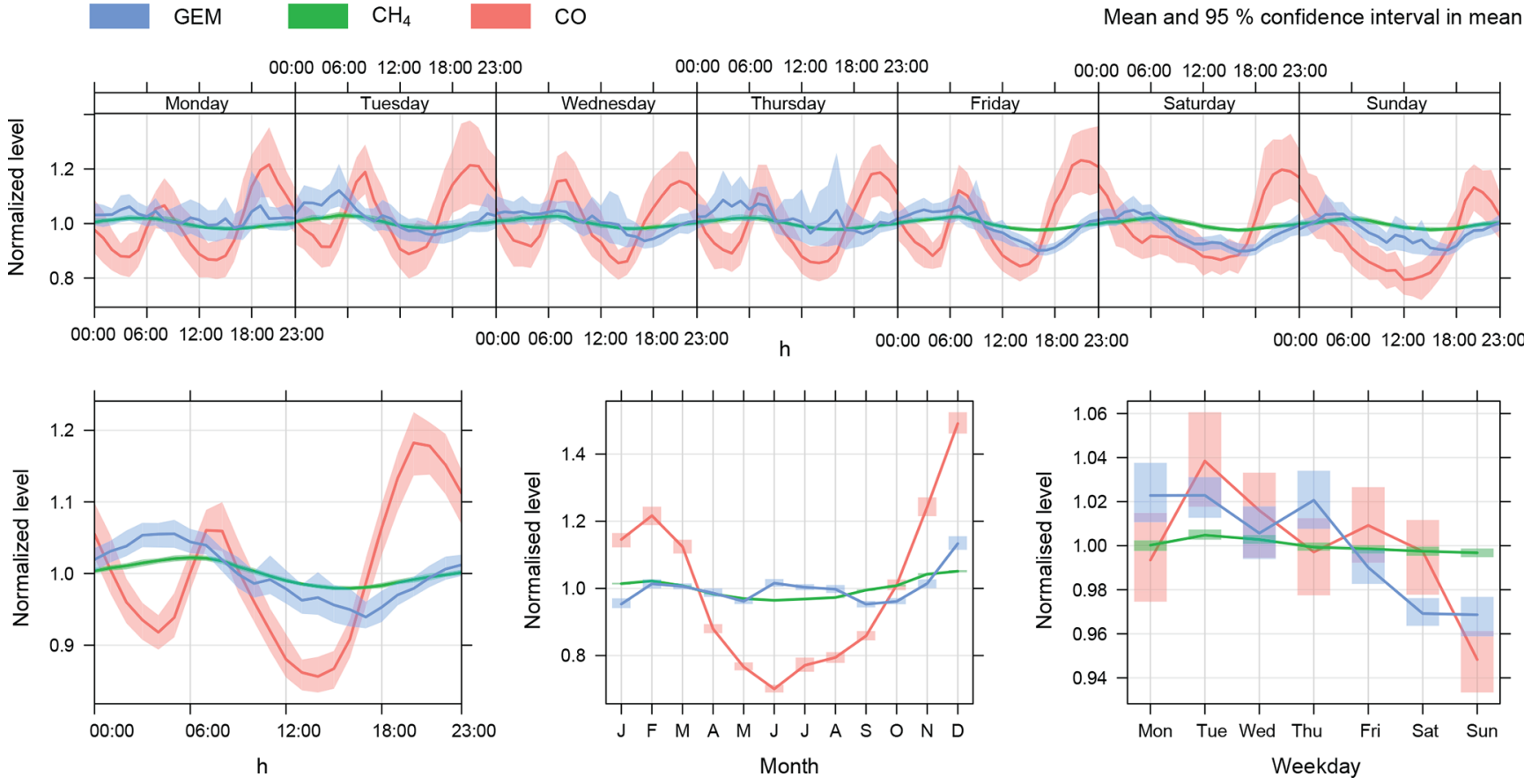

Figure 2. Comparison between normalized GEM, $\mathrm{CH}_{4}$ and $\mathrm{CO}$ levels (divided by overall mean) showing the temporal variation over a weekly, daily, monthly and weekday course. Mean values and $95 \%$ confidence intervals are shown. Source: NABEL (FOEN and Empa; BAFU/EMPA, 2018).

anti-cyclical to the wind speed and suggest a meteorological cause for the pattern. Stable conditions with lower wind speeds and lower boundary-layer height during the night lead to a slight concentration rise, while higher thermal convection during daytime lower these concentrations. The wind rose plots (Fig. S3) for GEM, $\mathrm{CH}_{4}$ and $\mathrm{CO}$ support these findings and our initial hypothesis of a constant source term of GEM for the city. GEM concentrations are thus primarily influenced by the wind speed and the diluting effect of lower background concentrations (Fig. S2). However, one can also observe slightly lower GEM concentration towards the weekend, with the lowest concentrations on Sundays (Fig. 2). More prominently this is the case for $\mathrm{CO}$, which has sources that are strongly activity-related, such as traffic. We therefore deduce that besides the prominent constant sources for GEM, there are also activity-related emissions but of a much smaller scale. The inversion events for the summer extracted from the measurement series show a clear diurnal trend not only for GEM but also for $\mathrm{CH}_{4}$ (Fig. S4); both trace gases stem from constant sources. In winter inversion periods concentrations for $\mathrm{PM}_{10}, \mathrm{CO}, \mathrm{SO}_{2}$ and $\mathrm{NO}_{x}$ also follow the course of GEM since combustion-related sources have a more constant source term (Fig. S5). These comparisons indicate that the emission flux for GEM and $\mathrm{CH}_{4}$ are constant over time.

For the measurement series at Zurich zoo on the outskirts of the city, a median GEM concentration of $1.62 \mathrm{ng} \mathrm{m}^{-3}$ $\left(Q_{0.1}=1.53 \mathrm{ng} \mathrm{m}^{-3}, Q_{0.9}=1.77 \mathrm{ng} \mathrm{m}^{-3}\right)$ was obtained.
GEM levels are significantly lower and the concentration range is much smaller at this measurement site - a clear indicator that this location is much less affected by local sources. Furthermore, these results confirm the assumption that background air is lower in concentration and suggest that background concentrations at a level of $1.5 \mathrm{ng} \mathrm{m}^{-3}$ are in fact a lower-bound estimate.

\subsection{Boundary-layer budget}

To illustrate the model results, we present the period showing longest continuing day-night inversion from 24 June until 6 July 2015 (Fig. 3) as an example. Analogous figures for the other eight inversion periods are shown in the Supplement (Figs. S6-S14). Figure 3 shows the most important model parameters: Fig. 3a shows the boundary-layer height, Fig. 3b shows the wind speed, and Fig. $3 \mathrm{c}$ shows the measured GEM concentrations (blue) and the model results (orange). GEM measurements show a clear diurnal variation with high concentrations of up to more than $3 \mathrm{ng} \mathrm{m}^{-3}$ during the night and lower concentrations during the day. The model results follow this pattern. The emissions strength of the city is observable from the steep concentration increase, when the BLH is lowered. These nocturnal periods with low wind speeds $\left(<2 \mathrm{~m} \mathrm{~s}^{-1}\right)$ are used to estimate the source term of the city. During daytime the modeled concentrations are dominated almost entirely by the background concentrations due to the 


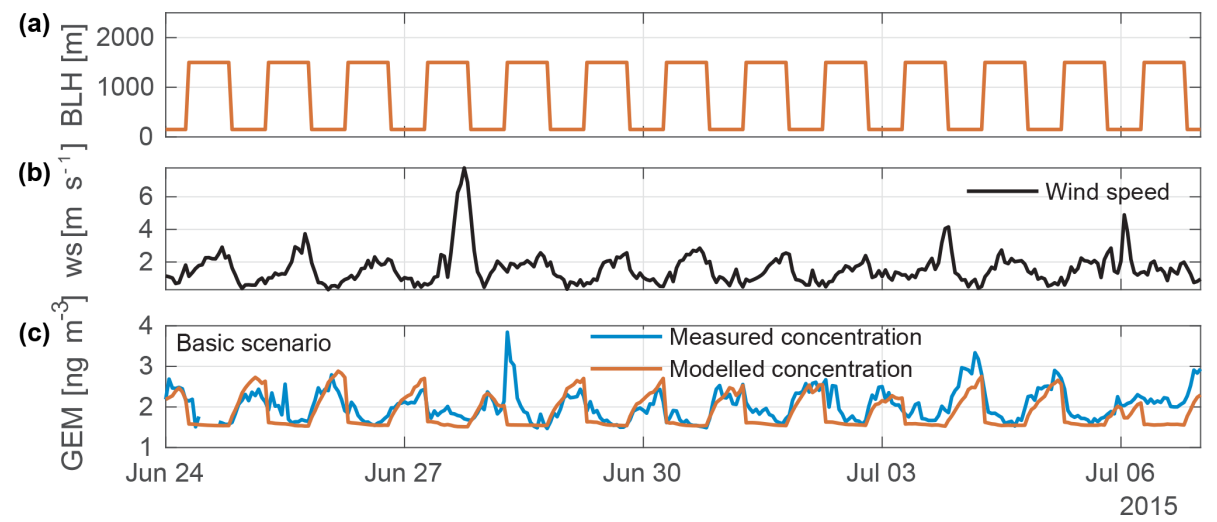

Figure 3. Example period from 24 June until 6 July 2015 that shows a day-night pattern for ground inversion. (a) shows the boundary-layer heights for the basic scenario (orange). (b) shows the wind speed (ws). (c) shows GEM measurements in blue and the basic model results in orange.

Table 1. The emission estimates of GEM in Zurich, Switzerland, are shown for all nine observed summer periods.

\begin{tabular}{lrrr}
\hline \multirow{2}{*}{ Start } & Days & \multicolumn{2}{c}{ Emissions $\left(\mathrm{g} \mathrm{h}^{-1}\right)$} \\
\cline { 3 - 4 } & & upper bound & lower bound \\
\hline 6 June 2014 & 4 & 5.7 & 3.8 \\
16 July 2014 & 5 & 4.4 & 2.5 \\
5 September 2014 & 4 & 4.0 & 2.4 \\
5 March 2015 & 6 & 3.5 & 1.7 \\
18 May 2015 & 5 & 3.4 & 1.1 \\
24 June 2015 & 14 & 4.8 & 3.0 \\
11 July 2015 & 13 & 5.9 & 3.8 \\
2 August 2015 & 5 & 5.7 & 3.7 \\
28 August 2015 & 4 & 4.5 & 2.7 \\
\hline Mean & & $4.7 \pm 0.9$ & $2.8 \pm 1$ \\
\hline Annual (kg a & & $41 \pm 8$ & $24 \pm 8$ \\
\hline
\end{tabular}

higher BLH and the stronger wind speeds, which create a much bigger flux than the city's GEM emissions.

In general, model results follow the measured concentration, suggesting advection and boundary-layer height are indeed enough to describe most of the GEM variation. During daytime, model results are slightly lower than measured GEM levels, showing that our model approach covers the most important atmospheric processes occurring on this timescale and successfully reproduces the fate of GEM in the urban air of Zurich. Using RMSE reduction we find a GEM emission flux of $4.8 \mathrm{~g} \mathrm{~h}^{-1}$ (Table 1) for the modeled region in this period, or $42 \mathrm{~kg} \mathrm{a}^{-1}$ when extrapolated to annual emissions for the city of Zurich. Over all nine periods, we find a mean emission of $4.7 \pm 0.9 \mathrm{~g} \mathrm{~h}^{-1}$ or $41 \pm 8 \mathrm{~kg} \mathrm{a}^{-1}$ (Table 1). The low variance of the emission estimate over all the nine periods from different months and years supports our claim of a constant mercury emission term for the city. Also for three winter periods with long stable inversion conditions
(Figs. S15-S17) emission estimates in the same range are observed (4.4 $\pm 0.8 \mathrm{~g} \mathrm{~h}^{-1}$; see Table S1 in the Supplement).

\subsubsection{Uncertainties of the emission estimates}

The mass balance for mercury in the air compartment of the box $(m)$ is formulated as follows:

$$
\begin{aligned}
& \frac{\mathrm{d} m}{\mathrm{~d} t}=V \cdot \frac{\mathrm{d} c}{\mathrm{~d} t}=F_{\mathrm{adv}} \cdot c_{\mathrm{back}}-F_{\mathrm{adv}} \cdot c(t)+E, \\
& \frac{\mathrm{d} m}{\mathrm{~d} t}=u \cdot A_{\mathrm{s}} \cdot c_{\mathrm{back}}-u \cdot A_{\mathrm{s}} \cdot c(t)+E,
\end{aligned}
$$

where $V\left(\mathrm{~m}^{3}\right)$ is the volume of the box, $c_{\text {back }}$ is the background concentration $\left(\mathrm{ng} \mathrm{m}^{-3}\right)$ and $E$ is the emission flux $\left(\mathrm{g} \mathrm{s}^{-3}\right)$. The advective air flux $F_{\text {adv }}\left(\mathrm{m}^{3} \mathrm{~s}^{-1}\right)$ is calculated from the wind with velocity $u\left(\mathrm{~m} \mathrm{~s}^{-1}\right)$ that flows through the lateral side of the box $A_{\mathrm{s}}\left(\mathrm{m}^{2}\right)$. Although the emission estimations presented so far are based on a dynamic timeresolved box model, we introduce here the steady-state case for the sake of simplification. For the steady-state solution $\left(\frac{\mathrm{d} m}{\mathrm{~d} t}=0\right)$ the emission flux is $E=u \cdot A_{\mathrm{s}} \cdot\left(c-c_{\text {back }}\right)$. The problems at hand are of a linear nature. Therefore, error handling is straightforward and the maximum error bound could be found using linear error propagation (MacLeod et al., 2002), and a given uncertainty in a parameter would at worst results in an equal uncertainty in the model result. However, the true errors of the parameters are unknown and not all of them would strictly follow a known distribution. The procedure we apply here leads to a more confident error margin.

As mentioned before, the background concentration, $c_{\text {back}}$, of $1.5 \mathrm{ng} \mathrm{m}^{-3}$ used until now is a lower bound for the background concentration that leads to an upper-bound estimate for the true GEM emissions. By using $1.8 \mathrm{ng} \mathrm{m}^{-3}$ as background concentration $(+20 \%)$, which is equal to the median and a high estimate for the background, we are able to set a lower bound for emissions. These two margins are more helpful in the error characterization than a technical error- 


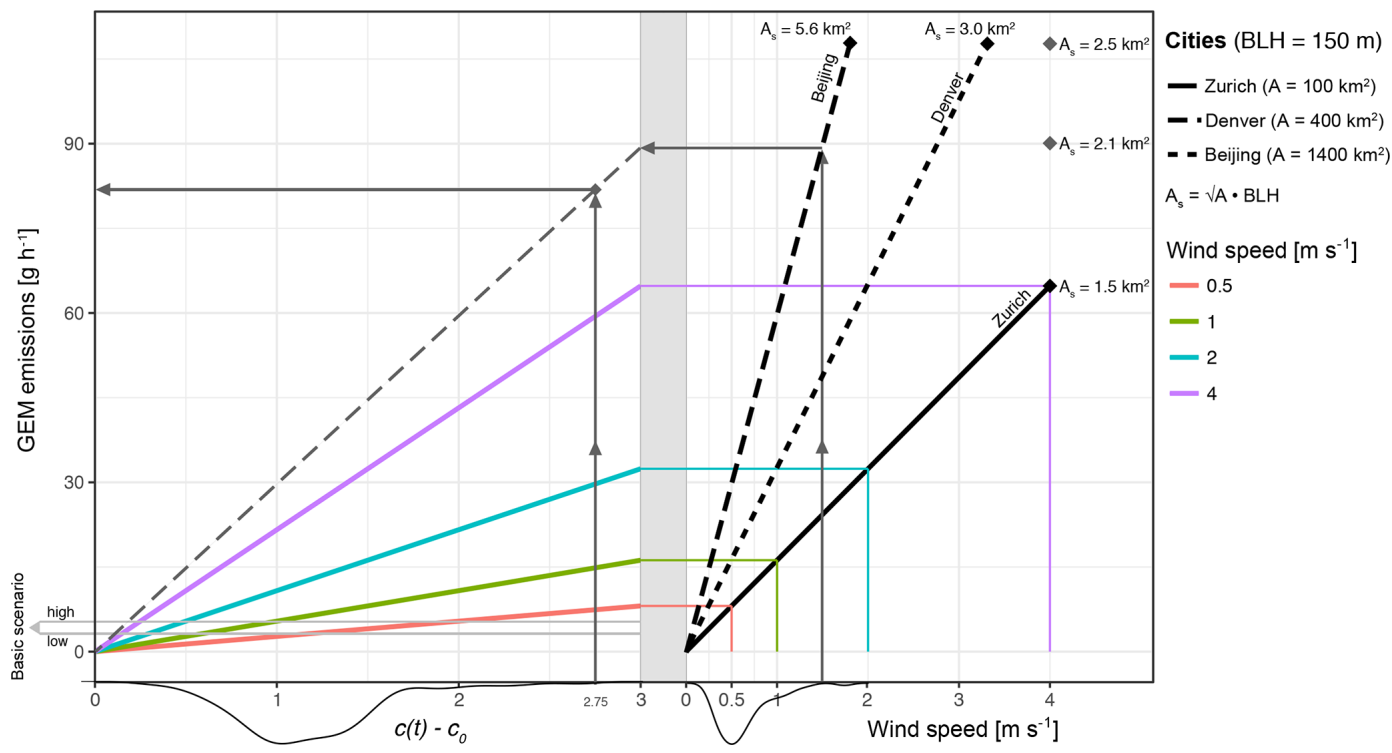

Figure 4. Graphical representation of the steady-state formula $E=u \cdot A_{\mathrm{s}} \cdot\left(c-c_{\text {back }}\right)$ to estimate emissions in a box model. Starting at different wind speeds, the colors show the corresponding GEM emission estimate for Zurich in relation to the concentration difference between measurement $c$ and background $c_{0}$. The results of the basic emission scenario are given as gray lines. The gray shading highlights the range in concentration differences obtained in Zurich. An example of how emissions are estimated for another city is given for Beijing, with a wind speed of $1.5 \mathrm{~m} \mathrm{~s}^{-1}$ and $2.6 \mathrm{ng} \mathrm{m}^{-3}$ concentration difference.

propagation approach. Following this approach we obtain a lower-bound emission of $2.8 \pm 1.0 \mathrm{~g} \mathrm{~h}^{-1}$ (Table 1 , mean of the lower-bound scenarios of the nine periods \pm standard deviation) and can thereby narrow down the true GEM emissions for Zurich. According to our findings they must amount to a value between $2.8 \pm 1.0$ and $4.7 \pm 0.9 \mathrm{~g} \mathrm{~h}^{-1}$. In this range we also see the sensitivity of the background concentration for the model results. As shown, a change in $c_{\text {back }}$ by $20 \%$ resulted in a mean emission estimate for all nine periods lower by $40 \%$. The sensitivity $(S=(\Delta O / O) /(\Delta I / I)$, MacLeod et al., 2002) of $c_{\text {back }}(I)$ regarding the mean emission estimate $(O)$ amounts to $S=2$.

After the background concentration, the BLH is the most sensitive parameter. An increase in the BLH by $10 \%$ results in an equally larger emission estimate: $S$ for the BLH equals 1 . As mentioned before the height of $150 \mathrm{~m}$ for Zurich has been established in previous model studies from temperature profiles. To test this value and the assumption of a constant height, we established an advanced model scenario, where the BLH is derived from a complex numerical weather prediction model (COSMO-2), developed by MeteoSwiss. The BLH is determined both for day and night with an hourly time resolution. The approach for the advanced scenario is presented in detail in the Supplement. All model runs of the advanced scenario are displayed in Figs. S6-S14. The emission estimates based on this advanced approach $\left(4.9 \pm 1.7 \mathrm{~g} \mathrm{~h}^{-1}\right.$, Table $\left.\mathrm{S} 1\right)$ are very close to the basic scenario with the fixed BLH presented here $\left(4.7 \pm 0.9 \mathrm{~g} \mathrm{~h}^{-1}\right)$. Additionally, the advanced model often does not provide a bet- ter model fit than the RMSE comparison show in Table S1. On this basis and in accordance with the outcome of the two model approaches, we favor the basic approach with a fixed $\mathrm{BLH}$ of $150 \mathrm{~m}$. The reason being that we can thereby reduce model complexity, which is not necessary to adequately describe the situation at hand.

Other important model parameters to be discussed here are the model area with a sensitivity of $S=0.6$ and the wind speed with a sensitivity of $S=0.4$. If we again look at a steady-state example $\left(\frac{\mathrm{d} m}{\mathrm{~d} t}=0\right)$ of Eq. (2) and rearrange to $c=c_{\text {back }}+E /\left(u \cdot A_{\mathrm{s}}\right)$, we see that the ratio between the emission flux $E$ and the advective flux $\left(u \cdot A_{\mathrm{s}}\right)$ determines the deviation of the concentration from the background concentration $c-c_{\text {back. }}$. During the day, advective fluxes are much larger than the emission term we estimate for Zurich. For the small box in Zurich even for very low wind speeds of $1 \mathrm{~m} \mathrm{~s}^{-1}, F_{\text {adv }}$ is 7 times bigger than $E$. Therefore, $c$ is dominated by $c_{\text {back }}$ during the day in our model. The explanatory power of the model is much stronger during the nocturnal inversion periods with low BLH and low wind speeds. During these periods advection has little influence. The model application domain for the two cases of high and low BLH are displayed in Fig. S18. These curves set the domain regarding the GEM concentrations explainable by our model depending on the BLH, the wind speed and the model area. The model area has to be chosen to encompass all important sources and be big enough to allow for a reasonable time step in the model setup. For large model areas, however, inhomogeneities in the model region could be problematic. Here, we 
Table 2. Swiss national inventory for mercury emissions in 2014 as submitted under the UNECE Convention on Long-Range Transboundary Air Pollution. (NFR: nomenclature for reporting emission categories, IPPU: industrial processes and product use).

\begin{tabular}{|c|c|c|c|}
\hline \multicolumn{2}{|c|}{ Hg emissions 2014} & \multirow{2}{*}{$\begin{array}{l}\text { National } \\
\left(\mathrm{kg} \mathrm{a}^{-1}\right)\end{array}$} & \multirow{2}{*}{$\begin{array}{r}\text { This study } \\
\left(\mathrm{kg} \mathrm{a}^{-1}\right)\end{array}$} \\
\hline NFR & Category & & \\
\hline 1 & power & 482 & \\
\hline $1 \mathrm{~A}$ & fuel combustion & 482 & \\
\hline A1 & energy industry & 279 & \\
\hline $\mathrm{A} 2: 5$ & miscellaneous & 162 & \\
\hline 2 & IPPU & 78 & \\
\hline 5 & waste & 35 & \\
\hline 6 & other & 63 & \\
\hline Total & & 658 & 574-951 \\
\hline
\end{tabular}

assume homogeneous distribution of GEM in our model region of $10 \mathrm{~km}$ by $10 \mathrm{~km}$. As work by Cairns et al. (2011) shows, GEM concentrations in Toronto do follow a certain distribution and differences in concentrations do occur depending on the measurement location. Our measurement site has been assessed for pollutants with diffuse emissions with passive samplers by comparing various sites throughout the city. The location proved to be a representative study site for an anthropogenic pollutant with diffuse emissions (Diefenbacher et al., 2015b, 2016). As mentioned before, mercury emissions in Zurich stem from diffuse sources, which are distributed in the whole city and a waste incineration plant in the city center. Emission estimates derived with our box model only apply to the whole city or can be averaged by person. Spatially resolved emission estimates are, however, not attainable.

The comparison of GEM measurements to $\mathrm{CO}$ and $\mathrm{CH}_{4}$ levels (see Figs. 2, S4 and S5) strongly suggests that GEM emissions in Zurich largely stem from constant sources. Activity-related emissions, i.e. from traffic, are a minor contributor. Also, from the comparison between summer and winter periods, which are comparable in terms of emission strength, we conclude that the increased combustion activities during the cold winter months are not a large contributor to overall GEM emissions. Possibly, increased GEM emissions from enhanced combustion activities in winter are compensated for by reduced emissions of GEM by evaporation from legacy mercury reservoirs in periods with low ambient temperatures and vice versa in winter.

\subsection{Implication on emission reporting}

Mercury emissions are annually reported by countries signatories to the Protocol on Heavy Metals to the UNECE Convention on Long-Range Transboundary Air Pollution (CLRTP). Swiss national CLRTP inventories for mercury emissions to the atmosphere reported a total of $658 \mathrm{~kg} \mathrm{a}^{-1}$ for the year 2014 (Heldstab et al., 2015). Mercury emissions are not differentiated by species: GEM or GOM. Due to the lack of these data we are forced to work with assumptions. Considering the nature of emission sources and relatively strict regulation on stack emissions, we assume all emissions to be in the form of GEM. The biggest share, $73 \%$ of the emissions, stems from the energy sector (1A1), of which the majority is allocated to energy industries for public electricity and heat production. The main sources to this energy sector are waste incineration plants. In Switzerland energy recovery from municipal solid waste incineration is mandatory and emissions from waste incineration plants are reported under this category. Other combustion processes mainly in manufacturing industries (1A2:5) make up $25 \%$ of the total emissions. These numbers and categorization into individual sectors and subcategories as shown in Table 2 and set the basis for the allocation to the global emission grid of the European Monitoring and Evaluation Programme (EMEP) for Switzerland. The grid shows spatially resolved emissions with a $0.1^{\circ} \times 0.1^{\circ}$ (approx. $\left.10 \mathrm{~km} \times 10 \mathrm{~km}\right)$ resolution. The allocation rules for the emissions rely mostly on population density and vary from one source category to another. Depending on the source category, different weightings on the prevailing employment sectors are installed. For Zurich, the gridded emissions report an emission flux of $18 \mathrm{~kg}$ for the year 2014 (18 kg for 2015). Our boundary-layer budget approach results in a GEM emission flux between 24 and $41 \mathrm{~kg}$ for Zurich. These findings suggest emission of about double the amount allocated to Zurich by the rule set for the EMEP report. If we were to apply the same allocation factors to the model results we would come up with national GEM emission of 934 to $1581 \mathrm{~kg} \mathrm{a}^{-1}$, i.e. clearly higher than reported by the authorities. When we use population data only as a criterion, a scaling factor of 20.5 would be appropriate, considering a population of approximately 400000 residents in the modeled area and a Swiss population of 8.2 million people. This approach would amount to emission of 494 to $837 \mathrm{~kg}$ GEM per year. In comparison to the $658 \mathrm{~kg} \mathrm{a}^{-1}$ of the Swiss CLRTP report, these results lie in a very acceptable range and show that the approach explained here can be used to validate national reporting. Moreover, from our results we suggest that the allocation formula for mercury for the EMEP grid should be adjusted such that population data are given more weight over other parameters. For Zurich we find a per capita emission of 0.06 to $0.10 \mathrm{~g} \mathrm{a}^{-1}$ per person. This estimate is somewhat lower than the European per capita emission of $0.19 \mathrm{~g} \mathrm{a}^{-1}$ reported in the AMAP/UNEP (2013) background report.

\section{General applicability and conclusions}

The boundary-layer approach presented here is based on atmospheric inversion. This phenomenon, however, is not unique only to Zurich but can be applied to a wide range 
of cities and industrial complexes of different size all over the world. Diurnal variability with higher nighttime GEM concentrations has for example been observed in southern England (Lee et al., 1998); Seoul, Korea (Kim and Kim, 2001); Guiyang, China (Feng et al., 2004); and Beijing and Guangzhou, China (Wang et al., 2007). By adapting the model to the localities, emission estimates are feasible and can support authorities in the setup and improvement of emission inventories. Indicators for inversion are manifold and are manifested by temperature inversion, increases in pollution levels or morning fog. The adaptiveness of the box model approach is displayed in Fig. 4. It shows a graphical representation of the steady-state equation for the emissions $\left(E=u \cdot A_{\mathrm{s}} \cdot\left(c-c_{\text {back }}\right)\right)$. We argue that steady state is reached to a reasonable degree when atmospheric conditions are stable for a period of several hours, depending though on the size of the box and the wind speed. The nomogram (Fig. 4) can be used in order to quickly estimate the emission strength of a city under the assumption of steady-state and well mixed conditions. Two example cities, Beijing (China) and Denver (CO, USA), of a different size are shown in the graph together with Zurich. All of them are located in a valley, which is a beneficial characteristic but not a requirement for the model. The starting point to read the graph marks the wind speed measured during an inversion period on the bottom right side of the graph. The graph to the left then gives the proportionality between the difference in GEM concentrations of the measurements and the background $\left(c-c_{0}\right)$ on the abscissa and the GEM emission strength on the axis of ordinates. A walk-through example is given for Beijing with a wind speed of $1.5 \mathrm{~m} \mathrm{~s}^{-1}$. Continuing in a straight path upwards (see gray vertical line on the right part of Fig. 4) the line given by the size of Beijing is reached (dashed black line). The box length for a city and the BLH define the lateral side of the box $A_{\mathrm{s}}$. Here, we use our standard BLH of $150 \mathrm{~m}$. From this point one draws a horizontal line to the left until the left plot is reached. A GEM concentration difference of $2.6 \mathrm{ng} \mathrm{m}^{-3}$ results in an emission estimate of $77.5 \mathrm{~g} \mathrm{~h}^{-1}$. Following this example, the emission strength of other cities can quickly be estimated according to size of their respective box model, the measured wind speeds and GEM concentrations. The colored lines show the situation in Zurich, i.e. the emission estimations with a wind speed of $0.5 \mathrm{~m} \mathrm{~s}^{-1}$ (red lines), $1 \mathrm{~m} \mathrm{~s}^{-1}$ (green lines), $2 \mathrm{~m} \mathrm{~s}^{-1}$ (blue lines), and $4 \mathrm{~m} \mathrm{~s}^{-1}$ (purple line). The distribution of the daily minimum wind speeds and the daily maximum concentration differences measured in Zurich during inversion are given by the density curves at the bottom. These curves set the bandwidths for GEM emissions predicted by the model. The emission estimates of the high and low backgrounds are given by the gray straight lines 2.8 and $4.7 \mathrm{~g} \mathrm{~h}^{-1}$. The comparison thereof with the emissions from the steady-state box model presented here shows a reasonable accordance.

Another entry point to read the graph is the emissions. For Beijing, emission estimates amount to $775 \mathrm{~g} \mathrm{~h}^{-1}\left(6.79 \mathrm{ta}^{-1}\right)$
(Streets et al., 2005; Wu et al., 2006; Zhou et al., 2010). Since the formula is all linear, both axes of the left graph can also be multiplied by 10 , so the entry is congruent to $77.5 \mathrm{~g} \mathrm{~h}^{-1}$. The concentration difference for a wind speed of $1.5 \mathrm{~m} \mathrm{~s}^{-1}$ then amounts to $26 \mathrm{ng} \mathrm{m}^{-3}\left(2.6 \mathrm{ng} \mathrm{m}^{-3} \times 10\right)$, which is a reasonable value for average concentrations in Beijing, considering the GEM measurements reported for the city (4-54 $\mathrm{ng} \mathrm{m}^{-3}$ ) (Wang et al., 2007; Zhou et al., 2010). Based on this preliminary assessment a more extensive box model study could be conducted, taking into account specific measurements and technical aspects such as the bigger air compartment, where the inhomogeneities in the air mixing have to be addressed with multiple measurement locations.

For a successful application of this approach, several aspects have to be considered. (i) Background levels should be stable and not directly influenced by large sources; furthermore, the influence of the wind direction has to be assessed. (ii) The model area has to be chosen wisely; when chosen too large it poses the problem of inhomogeneities in the air compartment, and when chosen too small it is dominated too much by advection, depending on wind speed and background GEM levels. (iii) The BLH should be stable and some knowledge about the BLH is a prerequisite; it is best to check for day-night inversions using another trace gas such as $\mathrm{CO}$ or $\mathrm{PM}_{10}$. (v) A closer look at local point sources within the model region is necessary, such as to assess whether they pose an overbalance compared to the diffuse emissions or whether their emissions, for example due to high stacks, are actually within the defined model boundaries.

We believe the boundary-layer budget approach presented here is a valuable contribution to the demand for mercury emission inventories by the UN Minamata Convention on Mercury (Article 19, 1.a). The low computational requirements a box model poses and its broad applicability make it a readily available tool that is needed in narrowing down the broader scope of common bottom-up emission estimates. The use of passive samplers for mercury, which allow a costeffective and broad spatial coverage in ambient air monitoring, in combination with box models such as ours pose a great opportunity not only for model refinement, but also for the applicability to other domains. Here, we see great potential of this boundary-layer approach to constrain the emission estimates of diffuse mercury emissions. The fields of application, however, are not limited to mercury alone - other compounds are also suited for emission estimates by a box model. Furthermore, besides emissions, sinks - a hot topic in mercury research - can also be quantified with the presented boundary-layer budget method.

Data availability. The underlying research data are available on request by contacting the authors. 
Supplement. The supplement related to this article is available online at: https://doi.org/10.5194/acp-19-3821-2019-supplement.

Author contributions. BD and CB planed the study, executed the measurements and prepared the manuscript. CK, AT and JH worked on the model development during their masters course. KH supervised the project.

Competing interests. The authors declare that they have no conflict of interest.

Acknowledgements. We would like to thank Stephan Henne (EMPA, Dübendorf) for the helpful advice he provided. Furthermore, we acknowledge the Swiss National Air Pollution Monitoring Network (NABEL) and the Federal Office for Meteorology and Climatology (MeteoSwiss) for providing measurement and meteorological data. We thank the Swiss Federal Office for the Environment (FOEN) for the project funding (grant numbers 00.0248.P2/M371-4632, 14.0039.KP/N412-1043).

Edited by: Manvendra K. Dubey

Reviewed by: two anonymous referees

\section{References}

AMAP/UNEP: Technical Background Report for the Global Mercury Assessment, Tech. Rep., UNEP, AMAP, Geneva, Oslo, 2013.

BAFU/EMPA: Messergebnisse 2016, Tech. Rep., BAFU, EMPA, Bern, 2018.

Benz, U.: Parametrisierung der planetaren Grenzschichthöhe über der Stadt Zürich, Diplomarbeit Geographisches Institut der ETH Zürich, 130 p., 1988.

Bogdal, C., Müller, C. E., Buser, A. M., Wang, Z., Scheringer, M., Gerecke, A. C., Schmid, P., Zennegg, M., Macleod, M., and Hungerbühler, K.: Emissions of polychlorinated biphenyls, polychlorinated dibenzo-p-dioxins, and polychlorinated dibenzofurans during 2010 and 2011 in Zurich, Switzerland, Environ. Sci. Technol., 48, 482-490, https://doi.org/10.1021/es4044352, 2014a.

Bogdal, C., Wang, Z., Buser, A. M., Scheringer, M., Gerecke, A. C., Schmid, P., Müller, C. E., MacLeod, M., and Hungerbühler, K.: Emissions of polybrominated diphenyl ethers (PBDEs) in Zurich, Switzerland, determined by a combination of measurements and modeling, Chemosphere, 116, 15-23, https://doi.org/10.1016/j.chemosphere.2013.12.098, 2014b.

Buchmann, B., Stemmler, K., and Reimann, S.: Regional emissions of anthropogenic halocarbons derived from continuous measurements of ambient air in Switzerland, CHIMIA International Journal for Chemistry, 57, 522-528, https://doi.org/10.2533/000942903777678966, 2003.

Buser, A. M., Kierkegaard, A., Bogdal, C., Macleod, M., Scheringer, M., and Hungerbühler, K.: Concentrations in ambient air and emissions of cyclic volatile methylsiloxanes in
Zurich, Switzerland, Environ. Sci. Technol., 47, 7045-7051, https://doi.org/10.1021/es3046586, 2013.

Buser, A. M., Bogdal, C., MacLeod, M., and Scheringer, M.: Emissions of decamethylcyclopentasiloxane from Chicago, Chemosphere, 107, 473-475, https://doi.org/10.1016/j.chemosphere.2013.12.034, 2014.

Cairns, E., Tharumakulasingam, K., Athar, M., Yousaf, M., Cheng, I., Huang, Y., Lu, J., and Yap, D.: Source, concentration, and distribution of elemental mercury in the atmosphere in Toronto, Canada, Environ. Pollut., 159, 2003-2008, https://doi.org/10.1016/j.envpol.2010.12.006, 2011.

Denmead, O. T., Raupach, M. R., Dunin, F. X., Cleugh, H. A., and Leuning, R.: Boundary layer budgets for regional estimates of scalar fluxes, Global Change Biol., 2, 255-264, https://doi.org/10.1111/j.1365-2486.1996.tb00077.x, 1996.

Diefenbacher, P. S., Bogdal, C., Gerecke, A. C., Glüge, J., Schmid, P., Scheringer, M., and Hungerbühler, K.: Emissions of Polychlorinated Biphenyls in Switzerland: A Combination of Long-Term Measurements and Modeling, Environ. Sci. Technol., 49, 2199 2206, https://doi.org/10.1021/es505242d, 2015a.

Diefenbacher, P. S., Bogdal, C., Gerecke, A. C., Glüge, J., Schmid, P., Scheringer, M., and Hungerbühler, K.: Short-Chain Chlorinated Paraffins in Zurich, Switzerland - Atmospheric Concentrations and Emissions, Environ. Sci. Technol., 49, 9778-9786, https://doi.org/10.1021/acs.est.5b02153, 2015b.

Diefenbacher, P. S., Gerecke, A. C., Bogdal, C., and Hungerbühler, K.: Spatial Distribution of Atmospheric PCBs in Zurich, Switzerland: Do Joint Sealants Still Matter?, Environ. Sci. Technol., 50, 232-239, https://doi.org/10.1021/acs.est.5b04626, 2016.

Feng, X. B., Shang, L. H., Wang, S. F., Tang, S. L., and Zheng, W.: Temporal variation of total gaseous mercury in the air of Guiyang, China, J. Geophys. Res.-Atmos., 109, 1-9, https://doi.org/10.1029/2003JD004159, 2004.

Gasic, B., Moecke, C., Macleod, M., Brunner, J., Scheringer, M., Jones, K. C., and Hungerbühler, K.: Measuring and modeling short-term variability of PCBs in air and characterization of urban source strength in zurich, Switzerland, Environ. Sci. Technol., 43, 769-776, https://doi.org/10.1021/es8023435, 2009.

Gasic, B., MacLeod, M., Klanova, J., Scheringer, M., Ilic, P., Lammel, G., Pajovic, A., Breivik, K., Holoubek, I., and Hungerbühler, K.: Quantification of sources of PCBs to the atmosphere in urban areas: A comparison of cities in North America, Western Europe and former Yugoslavia, Environ. Pollut., 158, 32303235, https://doi.org/10.1016/j.envpol.2010.07.011, 2010.

Gay, D. A., Schmeltz, D., Prestbo, E., Olson, M., Sharac, T., and Tordon, R.: The Atmospheric Mercury Network: measurement and initial examination of an ongoing atmospheric mercury record across North America, Atmos. Chem. Phys., 13, 1133911349, https://doi.org/10.5194/acp-13-11339-2013, 2013.

Hasenfratz, D., Saukh, O., Walser, C., Hueglin, C., Fierz, M., Arn, T., Beutel, J., and Thiele, L.: Deriving high-resolution urban air pollution maps using mobile sensor nodes, Pervasive Mob. Comput., 16, 268-285, https://doi.org/10.1016/j.pmcj.2014.11.008, 2015.

Heldstab, J., Herren, M., and Walder, J.: Switzerland's Informative Inventory Report 2015, Submission under the UNECE Convention on Long-range Transboundary Air Pollution, Tech. Rep., FOEN, Bern, 2015. 
Kim, K. H. and Kim, M. Y.: The temporal distribution characteristics of total gaseous mercury at an urban monitoring site in Seoul during 1999-2000, Atmos. Environ., 35, 4253-4263, https://doi.org/10.1016/S1352-2310(01)00214-X, 2001.

Lee, D. S., Dollard, G. J., and Pepler, S.: Gas-phase mercury in the atmosphere of the United Kingdom, Atmos. Environ., 32, 855864, https://doi.org/10.1016/S1352-2310(97)00316-6, 1998.

Lowry, D., Holmes, C. W., Rata, N. D., O'Brien, P., and Nisbet, E. G.: London methane emissions: Use of diurnal changes in concentration and $\delta^{13} \mathrm{C}$ to identify urban sources and verify inventories, J. Geophys. Res.-Atmos., 106, 7427-7448, https://doi.org/10.1029/2000JD900601, 2001.

MacLeod, M., Fraser, A. J., and Mackay, D.: Evaluating and expressing the propagation of uncertainty in chemical fate and bioaccumulation models, Environ. Toxicol. Chem., 21, 700-709, https://doi.org/10.1002/etc.5620210403, 2002.

MacLeod, M., Scheringer, M., Podey, H., Jones, K. C., and Hungerbühler, K.: The origin and significance of short-term variability of semivolatile contaminants in air, Environ. Sci. Technol., 41, 3249-3253, https://doi.org/10.1021/es062135w, 2007.

Mueller, M. D., Wagner, M., Barmpadimos, I., and Hueglin, C.: Two-week $\mathrm{NO}_{2}$ maps for the City of Zurich, Switzerland, derived by statistical modelling utilizing data from a routine passive diffusion sampler network, Atmos. Environ., 106, 1-10, https://doi.org/10.1016/j.atmosenv.2015.01.049, 2015.

Mueller, M. D., Hasenfratz, D., Saukh, O., Fierz, M., and Hueglin, C.: Statistical modelling of particle number concentration in Zurich at high spatio-temporal resolution utilizing data from a mobile sensor network, Atmos. Environ., 126, 171-181, https://doi.org/10.1016/j.atmosenv.2015.11.033, 2016.

Müller, C. E., Gerecke, A. C., Bogdal, C., Wang, Z., Scheringer, M., and Hungerbühler, K.: Atmospheric fate of poly- and perfluorinated alkyl substances (PFASs): I. Day-night patterns of air concentrations in summer in Zurich, Switzerland, Environ. Pollut., 169, 196-203, https://doi.org/10.1016/j.envpol.2012.04.010, 2012.

Nisbet, E. and Weiss, R.: Atmospheric science, Top-down versus bottom-up, New York, Science, 328, 1241-1243, https://doi.org/10.1126/science.1189936, 2010.

Salmond, J. A.: Wavelet analysis of intermittent turbulence in a very stable nocturnal boundary layer: Implications for the vertical mixing of ozone, Bound.-Lay. Meteorol., 114, 463-488, https://doi.org/10.1007/s10546-004-2422-3, 2005.

Schuhmacher, P.: No TitleMessung und numerische Modellierung des Windfeldes über einer Stadt in komplexer Topographie, Ph.D. thesis, ETH Zürich, https://doi.org/10.3929/ethz-a000599817, 1992.
Streets, D. G., Hao, J., Wu, Y., Jiang, J., Chan, M., Tian, H., and Feng, X.: Anthropogenic mercury emissions in China, Atmos. Environ., 39, 7789-7806, https://doi.org/10.1016/j.atmosenv.2005.08.029, 2005.

Stull, R. B.: Mean Boundary Layer Characteristics, in: An Introduction to Boundary Layer Meteorology, Springer Netherlands, Dordrecht, 1-27, https://doi.org/10.1007/978-94-009-3027-8_1, 1988.

van Velzen, D., Langenkamp, H., and Herb, G.: Review: Mercury in waste incineration, Waste Manage. Res., 20, 556-568, https://doi.org/10.1177/0734242X0202000610, 2002.

Wang, Z., Scheringer, M., MacLeod, M., Bogdal, C., Müller, C. E., Gerecke, A. C., and Hungerbühler, K.: Atmospheric fate of polyand perfluorinated alkyl substances (PFASs): II. Emission source strength in summer in Zurich, Switzerland, Environ. Pollut., 169, 204-209, https://doi.org/10.1016/j.envpol.2012.03.037, 2012.

Wang, Z.-W., Chen, Z.-S., Duan, N., and Zhang, X.-S.: Gaseous elemental mercury concentration in atmosphere at urban and remote sites in China, J. Environ. Sci., 19, 176-180, https://doi.org/10.1016/S1001-0742(07)60028-X, 2007.

Wilson, S. J., Steenhuisen, F., Pacyna, J. M., and Pacyna, E. G.: Mapping the spatial distribution of global anthropogenic mercury atmospheric emission inventories, Atmos. Environ., 40, 46214632, https://doi.org/10.1016/j.atmosenv.2006.03.042, 2006.

Wu, Y., Wang, S., Streets, D. G., Hao, J., Chan, M., and Jiang, J.: Trends in anthropogenic mercury emissions in China from 1995 to 2003, Environ. Sci. Technol., 40, 5312-5318, https://doi.org/10.1021/es060406x, 2006.

Zhang, L., Wang, S., Wu, Q., Wang, F., Lin, C.-J., Zhang, L., Hui, M., Yang, M., Su, H., and Hao, J.: Mercury transformation and speciation in flue gases from anthropogenic emission sources: a critical review, Atmos. Chem. Phys., 16, 2417-2433, https://doi.org/10.5194/acp-16-2417-2016, 2016.

Zhou, X., Du, J., Wang, C., and Liu, S.: Source apportionment and distribution of atmospheric mercury in urban Beijing, China, Chinese Journal of Geochemistry, 29, 182-190, https://doi.org/10.1007/s11631-010-0182-y, 2010.

Zinchenko, A. V., Paramonova, N. N., Privalov, V. I., and Reshetnikov, A. I.: Estimation of methane emissions in the St. Petersburg, Russia, region: An atmospheric nocturnal boundary layer budget approach, J. Geophys. Res.-Atmos., 107, 4416, https://doi.org/10.1029/2001JD001369, 2002. 